\title{
Brief hospitalization protocol for pressure ulcer surgical treatment: outpatient care and one-stage reconstruction
}

\section{Protocolo de internação breve para tratamento cirúrgico de lesões por pressão: preparo ambulatorial e cobertura em tempo único}

Dimas André Milcheski'; Rogério Rafael da Silva Mendes' ${ }^{1}$; Fernando Ramos de Freitas ${ }^{1}$; Guilherme Zaninetti'; Araldo Ayres Moneiro JÚNIOR'; ROLF GEMPERLI, TCBC-SP'1.

A B S T R A C T

\begin{abstract}
Objective: to evaluate a brief hospitalization protocol for the treatment of pressure ulcers, proposed by the Complex Wound Group of Clinical Hospital of University of Sao Paulo Medical School, particularly in regard to selection of patients, hospitalization time, cutaneous covering, complications and sore recurrence. Methods: retrospective cohort of 20 consecutive patients with 25 pressure lesions Grade IV. All patients were ambulatorily prepared and were hospitalized for surgical one time procedure for pressure lesion closing. Results: in total, 27 flaps were performed to close 25 wounds. Three patients showed minor dehiscence (11.1\%). There was no recurrence during the post-surgical follow-up period. No patient suffered a new surgery and no flap showed partial or total necrosis. Median time of hospitalization was 3.6 days (2-6 days) and median follow-up was 91 months (2-28 months). All patients maintained their lesions closed, and there was no recurrence during follow-up. Conclusion: the brief hospitalization protocol was considered adequate for the resolution of pressure wounds, showing an average time of hospitalization of 3.6 days and rate of minor surgical wound dehiscence of $11.1 \%$.
\end{abstract}

Keywords: Pressure Ulcer. Wounds and Injuries. Surgical Flaps. Surgery, Plastic.

\section{INTRODUCTION}

T reatment of complex wounds is part of the job of the Plastic Surgeon. Population aging and complications of diseases such as diabetes and neurological disturbances are relevant to the occurrence of such wounds. Among several causes, pressure ulcers/sores may be highlighted, resulting from continuous ischemia over bone prominences ${ }^{1,2}$. Usually, they are observed in paralysed or unconscious patients that cannot feel or respond to periodic need of repositioning ${ }^{3}$. Preventive measures include identification of high risk patients and their constant clinical evaluation, programmed repositioning, use of mattress that relief pressure and of barriers to local moisture, and correct nutrition. Prevention of such lesions directly reflects hospital care and multidisciplinary coordinated approach of health teams ${ }^{4}$.

The National Pressure Ulcer Advisory Panel (NPUAP), in 1989, proposed a classification of pressure ulcers that was revised in $2007^{5}$. It considers the depth of tissue damage, exposition of deep structures (muscles, tendons, bones) and the presence of contamination and slough. The classification ranges from I to IV and the highest score is related to lesions with loss of total tissue thickness, exposing muscles and bones.

At Clinicas Hospital of the University of São Paulo (HC-FMUSP) (São Paulo, Brazil), the Group for treatment of complex wounds is part of Plastic Surgery Department and attends patients with pressure wounds at the Emergency Room, Hospital or Ambulatory. Over the last years, it has been observed an increase of referred patients to our Ambulatory with pressure ulcers. In response to that, a protocol for pre-operatory care of patients was developed by the plastic surgery team for the treatment of pressure lesions with good clinical conditions that could be taken care with a short period of hospitalization, in order to provide a one-stage surgery for closure of wounds.

The objective of the present study was to evaluate a brief hospitalization protocol for the treatment of pressure wounds proposed by the Complex

1 - Faculty of Medicine, University of São Paulo, Plastic Surgery Division, Hospital das Clínicas, São Paulo, SP, Brasil. 
Wound Group of HC-FMUSP with emphasis on the patients selection, period of hospitalization, type of cutaneous covering, complications and recurrence of wounds.

\section{METHODS}

This was a retrospective cohort study that evaluated 20 consecutive patients with 25 grade IV lesions. They were treated from 2016 to 2017 at ambulatory and admitted according to the brief hospitalization protocol for surgical treatment, with the following selection criteria: Grade IV pressure wounds; Albumin >3.0; Hemoglobin >10.0; Controlled spasticity; Clean wound, with borders showing regression; Absence of clinical signals and/or image exams suggesting osteomyelitis; Familial or caregiver support.

Patients were followed-up at ambulatory after discharge for evaluation of: healing/absence of dehiscence (up to 30 days) or recurrence (more than 30 days). Minor dehiscence was considered when it was possible to treat with ambulatory dressings and it was considered major when it was necessary a new surgery. Patients that did not match the inclusion criteria were excluded as well as those with loss of postoperative follow-up. Patients with comorbidities or who smoked were not excluded.

Regarding surgical technique, it followed a standard procedure: extended bursectomy and debridement until a clinically viable bone was reached; these were followed by immediate reconstruction with a fasciocutaneous loco-regional flap. An exception was made to trochanteric lesions that were covered with a miocutaneous fascia lata tensor flap (Figure 1). The performed flaps had about $20 \%$ to $40 \%$ of their extent de-epidermised and they were inserted inside the wound for bone protection and filling of the dead space. All patients were drained and samples of deep bone tissue were sent to pathological analysis, in order to rule out the presence of chronic osteomyelitis and to guide post -operatory antibiotic therapy.

Patients with pressure lesions in more than one location were treated according to the possibility of alternate decubitus during post-operatory period for adequate recovery and avoidance of new wounds.

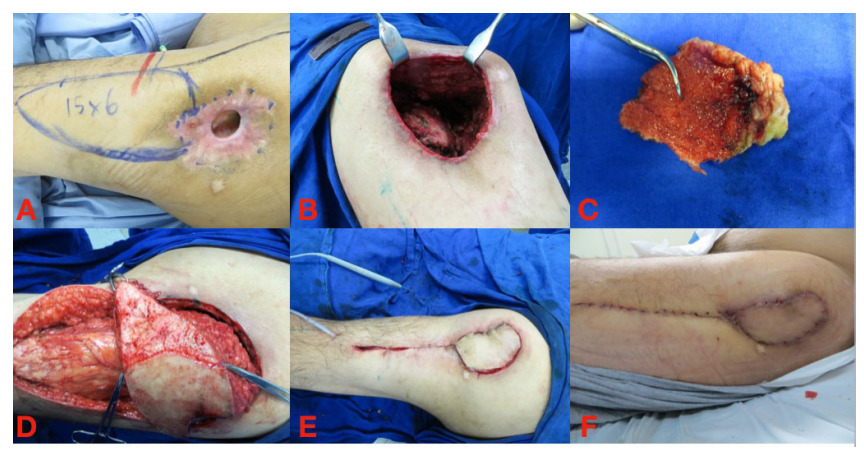

Figure 1. Trochanteric pressure ulcer.

(Patient 3)- Trochanteric pressure lesion. A) marking of fascia lata tensor miocutaneous flap; $B$ ) extensive cavity defect after bursectomy; C) partial resection of trochanter; D) the flap was resected and de-epidermised for filling the defect; E) immediate post-operatory with covering and filling the defect; F) two months post-operatory.

\section{RESULTS}

Median age of patients was 38.1 years (2275 years old). Seventeen patients (85\%) were male and three $(15 \%)$ female. Fifteen patients $(75 \%)$ were paraplegic, three tetraplegic (15\%) and two (10\%) presented a chronic degenerative disease that caused immobilization.

Median hemoglobin level was $13.1 \mathrm{~g} / \mathrm{dl}$ (10.3 to 15.5), and median albumin was $4.0 \mathrm{~g} / \mathrm{dl}$ (3.1 to 4.7$)$. Five patients used drugs to control spasticity (25\%). Controlled spasticity is related to the ability of patients to change and maintain a different decubitus. No patients had been previously submitted to surgical treatment of their wounds. Epidemiological data of each operated patient are listed at table 1.

Results of surgical procedures are listed at table 2 .

In total, 27 flaps were made to cover 25 wounds. Among these, $3(11.1 \%)$ showed minor dehiscence (treated only with ambulatory dressings) and one hematoma (3.7\%) without the need of surgical drainage. There were no recurrences at follow up period. No patient suffered a new surgery and no flap presented partial or total necrosis (Figure 2).

Bone sample analysis after surgical debridement were positive in five patients. They received prolonged antibiotic therapy according to sensitivity and none presented surgical wound infection or dehiscence. Among five patients with spasticity, one presented minor dehiscence and another a hematoma at post-operatory period (treated conservatively). 
Table 1. Epidemiological data of operated patients.

\begin{tabular}{lcccc}
\hline & Age & Gender & Immobilization & Topography of the lesion \\
\hline Patient 1 & 35 & M & Paraplegia & Ischium and sacrum \\
Patient 2 & 28 & M & Immobilization & Sacrum \\
Patient 3 & 75 & F & Paraplegia & Ischium and trochanter \\
Patient 4 & 31 & M & Paraplegia & Sacrum and bilateral ischium \\
Patient 5 & 37 & F & Paraplegia & Sacrum and unilateral ischium \\
Patient 6 & 22 & M & Immobilization & Bilateral trochanter \\
Patient 7 & 24 & M & Paraplegia & Sacrum \\
Patient 8 & 69 & M & Paraplegia & Bilateral trochanter \\
Patient 9 & 31 & M & Paraplegia & Ischium unilateral \\
Patient 10 & 22 & M & Tetraplegia & Sacrum \\
Patient 11 & 24 & M & Paraplegia & Sacrum and unilateral ischium \\
Patient 12 & 40 & M & Tetraplegia & Unilateral sacrum and \\
& & & & trochanter \\
Patient 13 & 54 & M & Paraplegia & Sacrum, trochanter and \\
Patient 14 & unilateral ischium \\
Patient 15 & M & Paraplegia & Sacrum and unilateral ischium \\
Patient 16 & 24 & M & Paraplegia & Unilateral ischium \\
Patient 17 & 30 & M & Paraplegia & Unilateral trochanter \\
Patient 18 & 28 & M & Paraplegia & Bilateral ischium \\
Patient 19 & 43 & F & Tetraplegia & Sacrum \\
Patient 20 & 35 & Paraplegia & Bilateral ischium \\
\hline
\end{tabular}

Table 2. Surgical procedures

\begin{tabular}{|c|c|c|}
\hline & Lesion & Flap \\
\hline Patient 1 & Ischium & Posterior thigh VY \\
\hline Patient 2 & Sacrum & Gluteus VY \\
\hline Patient 3 & Ischium and Unilateral Trochanter & Posterior thigh $\mathrm{VY}+$ fascia lata tensor \\
\hline Patient 4 & Bilateral Ischium & Bilateral posterior thigh $\mathrm{VY}$ \\
\hline Patient 5 & Sacrum & Bilateral gluteus VY \\
\hline Patient 6 & Trochanter Unilateral Trochanter & Fascia Lata tensor \\
\hline Patient 7 & Sacrum & Gluteus VY \\
\hline Patient 8 & Bilateral Ischium & Bilateral posterior thigh $\mathrm{VY}$ \\
\hline Patient 9 & Ischium & Posterior thigh $\mathrm{VY}$ \\
\hline Patient 10 & Sacrum & Gluteus VY \\
\hline Patient 11 & Sacrum & Bilateral gluteus VY \\
\hline Patient 12 & Sacrum & Gluteus VY \\
\hline Patient 13 & Sacrum & Gluteus VY \\
\hline Patient 14 & Ischium & Posterior thigh $\mathrm{VY}$ \\
\hline Patient 15 & Ischium & Posterior thigh $\mathrm{VY}$ \\
\hline Patient 16 & Unilateral Trocanter & Fascia Lata tensor \\
\hline Patient 17 & Bilateral Ischium & Bilateral posterior thigh $\mathrm{VY}$ \\
\hline Patient 18 & Sacrum & Gluteus VY \\
\hline Patient 19 & Bilateral Ischium & Bilateral posterior thigh $\mathrm{VY}$ \\
\hline Patient 20 & Ischium & Posterior thigh $\mathrm{VY}$ \\
\hline
\end{tabular}


Medium time of hospitalization was 3.6 days (2-6 days), medium follow-up was 9.1 months (2-18 months). All patients maintained their wound closed and none of them showed recurrence during the follow-up period. Outcome data are described at table 3.

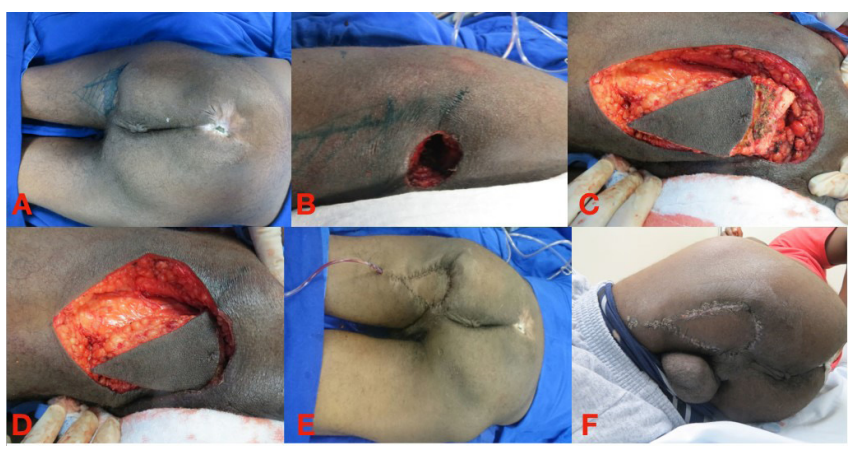

Figure 2. Ischiatic pressure lesion.

(Patient 9)- Ischiatic pressure lesion. A) marking of posterior fasciocutaneous thigh flap; B) defect after bursa resection; C) the flap was dissected and partially de-epidermised; D) inserted flap fixed at ischium periosteum for filling and protection; E) immediate post-operatory; F) one month of post-operatory with stable covering.

\section{DISCUSSION}

Over the last years it was observed an increase of referred patients to our ambulatory with pressure lesions; this can be explained by many reasons, such as no resolution of pressure sore during acute phase of hospitalization, recurrence of previous operated wounds, fail to follow guidelines of local care and change of decubitus, low socio-economic level of patients and absence of a caregiver to help with local care and change of decubitus.

Pressure wounds have different prevalence according to countries and regions, maybe due to health local systems, HDI, per capita income, culture, etc. However, several location data show a relatively constant and convergent prevalence. In developed countries, risk patients have a prevalence of $1 \%$ to $50 \%$ (inpatients) and $8.3 \%$ (at home). In Germany, $21.2 \%$ of inpatients and $8.3 \%$ at home have pressure wounds. In the U.S.A., prevalence varies from $2 \%$ to $28 \%$ (medium $11 \%)^{6}$.

Table 3. Outcome data.

\begin{tabular}{lccccc}
\hline & Osteomyelitis & Complications & $\begin{array}{c}\text { Hospitalization } \\
\text { (days) }\end{array}$ & $\begin{array}{c}\text { Follow-up } \\
\text { (months) }\end{array}$ & $\begin{array}{c}\text { Stable covering } \\
(1 \text { month) }\end{array}$ \\
\hline Patient 1 & Yes & No & 4 & 18 & Yes \\
Patient 2 & No & Dehiscence & 2 & 16 & Yes \\
Patient 3 & No & No & 2 & 15 & Yes \\
Patient 4 & Yes & No & 4 & 14 & Yes \\
Patient 5 & No & No & 4 & 14 & Yes \\
Patient 6 & Yes & No & 4 & 12 & Yes \\
Patient 7 & No & Hematoma & 4 & 12 & Yes \\
Patient 8 & Yes & No & 4 & 11 & Yes \\
Patient 9 & No & No & 4 & 10 & Yes \\
Patient 10 & Yes & No & 5 & 9 & Yes \\
Patient 11 & No & No & 6 & 9 & Yes \\
Patient 12 & No & No & 4 & 8 & Yes \\
Patient 13 & No & No & 3 & 7 & Yes \\
Patient 14 & No & No & 6 & 6 & Yes \\
Patient 15 & No & No & 3 & 6 & Yes \\
Patient 16 & No & No & 6 & 4 & Yes \\
Patient 17 & No & Dehiscence & 2 & 4 & Yes \\
Patient 18 & No & Dehiscence & 2 & 3 & Yes \\
Patient 19 & No & No & 2 & 2 & Yes \\
Patient 20 & No & No & 2 & 2 & Yes \\
\hline
\end{tabular}


In Brazil, pressure lesions prevalence is $16.9 \%$ for risk patients that rises to $39.4 \%$ for those with more than 60 years old. A study by the Federal University of Minas Gerais (UFMG) involving hospitals all over the country, studied 473 patients (251 men and 222 women) with 18 to 103 years old (medium 58.4 years); it observed pressure lesions in 80 patients (16.9\%) with 137 ulcers. Among those patients, $47.4 \%$ had nutrition deficiency and $52.6 \%$ some grade of malnutrition ${ }^{7}$. Another aggravating factor is the immobilization grade of patient. The lowest the ability to move the higher the probability of a more severe lesions. Among tetraplegics and paraplegics, prevalence of pressure ulcers is $20 \%$ to $60 \%$. Around $85 \%$ of patients with spinal cord injury may develop pressure lesions during treatment ${ }^{8,9}$.

Most affected sites by pressure lesions are sacral and trochanteric regions. In a study by the Institute of Orthopedics and Trauma from HC-FMUSP including 45 patients, $32.5 \%$ of pressure lesions were sacral, $32.5 \%$ trochanteric, $15.5 \%$ involved ischium and $19.5 \%$ other regions. UFMG cited study included 137 lesions, and 66 (48.1\%) were sacral, 30 (21.9\%) trochanteric, 22 (16\%) calcaneus and 21 (15.3\%) involved other sites ${ }^{10}$.

In our cohort, $46.8 \%$ of pressure sores were ischiatic, mainly in male patients (84\%), adults at working age (medium 38.8 years) and paraplegics (73.5\%). These data may represent a selection bias of the brief hospitalization protocol for patients with ischiatic lesions with better pre-operatory conditions. In general, two distinct epidemiologic population with pressure lesions are observed. One aged, with severe comorbidities (cardiopathies and neuropathies), with low level of conscience and lesions related to horizontal decubitus position (Figure 3). The other includes young patients, victims of spinal cord injury, usually paraplegics, with pressure lesions related to seated orthostatic position (wheelchairs). The first population presents mainly ulcers at sacrum and trochanter, and the other, at ischium (uni or bilateral).

Initial treatment of these lesions include local pressure relief, improvement of spasms, usually frequent in these patients, enzymatic or surgical debridement, and maintenance of a clean and moistu- re environment that allows for granulation and re-epithelization of the wound bed ${ }^{11}$. Approximately 70 to $90 \%$ of pressure ulcers are superficial and heal by second intention with these cares. Lesions Grades III and IV, deeper and occasionally associated with osteomyelitis, usually need surgical treatment, require covering with flaps for definitive treatment. In those patients, it is important to optimize home care (change of decubitus, local care) and nutritional status in order to increase surgical success ${ }^{12}$.

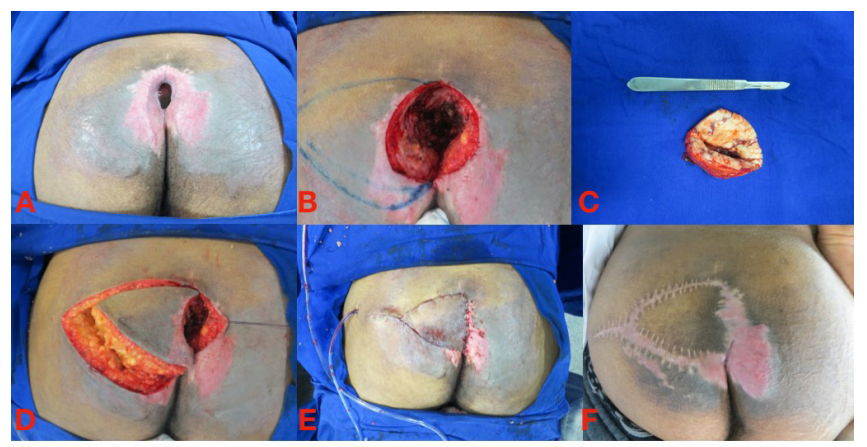

Figure 3. Sacral pressure ulcer.

(Patient 10)-Sacral pressure lesion. A) wound; B) defect after bursa resection; $C$ part resected; D) dissection and advance of gluteus fasciocutaneous $V-Y$ flap; E) immediate post-operatory with covering of defect; F) six months of post-operatory with stable covering.

Our department chose to perform predominantly fasciocutaneous flaps routinely, since they provide adequate covering, good filling when de-epidermised and full irrigation of the wound, aiding infection control. Classically, the first option would be miocutaneous flaps, however, more recent papers showed similar quality of covering ${ }^{13}$. On the other side, muscular tissue is more sensitive to ischemia, increases operatory morbidity and prevents future use in case of recurrence ${ }^{14}$.

This protocol selection variables and their cut-off values reflect the intention to perform the most successful resolutive surgery possible, with lower hospitalization time, and lower complication rate, in order to optimize the use of hospital beds and surgical rooms available. Grade IV pressure lesions were included due to the severity of these lesions that expose deep structures and need covering with flaps. In literature, hemoglobin level above $10 \mathrm{~g} / \mathrm{dl}$ is a very important cut-off, as well as serum albumin above 
$3.0 \mathrm{~g} / \mathrm{dl}$, that reflect a good nutritional status related to lower rate of dehiscence of surgical wound ${ }^{15,16}$.

The presence of spasticity in patients with pressure lesions is another important aspect ${ }^{17}$, since it difficult or prevents change of decubitus. These patients are at higher risk of presenting pressure ulcers, or recurrence in operated or healed areas. Usually, therapeutic options include baclofen associated or not with benzodiazepines. In the studied cohort, five patients were controlled with drugs.

The absence at pre-operatory of osteomyelitis was also observed for inclusion of patients at the short hospitalization protocol, since it lowers surgical success rate ${ }^{18}$. In case of clinical (presence in inflammatory signs, fever, purulence) or laboratory (increase of leucocytes and PCR) suspicion, nuclear magnetic resonance was performed to confirm or rule out osteomyelitis. If positive, the patient was referred to Orthopedic Department for multidisciplinary treatment. If negative, the patient was included. At present, magnetic resonance is considered the best study for diagnosis of osteomyelitis ${ }^{19}$. However, the surgical protocol included partial resection of bone prominence to attenuate the pressure point that was sent to pathological analysis. Five samples were positive for osteomyelitis at post-operatory. The use and period of use of antibiotics according to sensitivity varied from 14 to 28 days, and, interestingly, no patient with positive culture had complications or presented signs of osteomyelitis during ambulatory follow-up. It is possible that complete debridement and partial resection of bone prominences until viable bone were important for these results, as well as a vascularized flap that provided oxygen and nutrients needed for the treatment of this condition.

The presence of a family member or caregiver during treatment of pressure lesions is vital for success $^{16}$. Therefore, this was another inclusion criteria included in the present study. It is critical for the patient to change position (dorsal to lateral, lying to seated) and this must be done very carefully with the aid of another person during the first four weeks of post-operatory. One of the three dehiscence lesions was observed on the seventh day of post-operatory, due to mechanical trauma caused directly by change of position. Therefore, during pre-operatory visit, it was reinforced the need of familial involvement or the constant presence of a caregiver. Indirectly, it was also observed if the patient came to pre-operatory consultation with the wound in good conditions (clean, correct dressing, regression borders) and if hygiene conditions were adequate. If positive, the patient was considered eligible for the protocol.

In view of the growing number of non-operated pressure lesions and the logistic difficulty to admit and operate these patients, it was proposed this short hospitalization protocol to treat pressure lesions grade IV. The patient is prepared at ambulatory and selected if fulfilled the inclusion criteria. Three goals were anticipated: 1) Lowering of hospitalization time; 2) Lowering of post-operatory dehiscence and wound complications; 3) Obtaining a stable covering with lower recurrence. In view of the obtained results (3.6 days of hospitalization, $11.1 \%$ of minor dehiscence and absence of recurrence) it is possible to affirm that goals were met. Literature historical data are in accordance to these results. Sameem et al. ${ }^{20}$ in a systematic review of 55 published studies, observed with fasciocutaneous flaps $11.7 \%$ of complications $(5.1 \%$ of flap necrosis), $6.9 \%$ of post-operatory infection and a medium of $11.2 \%$ of recurrence (13 to $31 \%$ ).

Regarding medium follow-up of 9.1 months, this time interval may be considered relatively short for an accurate analysis. It must be observed that these patients have reduced mobility and depend on familial members and transport to attend ambulatory visits. Therefore, many patients are lost for follow-up, when their wounds are healed. It is important to mention that time interval to observe recurrence is higher than the one here reported, around 12 to 24 months.

We concluded that the brief hospitalization protocol was considered adequate for the resolution of pressure wounds, with low time of hospitalization and low level of surgical wound dehiscence. 


\title{
R E S U M O
}

\begin{abstract}
Objetivo: avaliar o protocolo de internação breve para tratamento de lesões por pressão, em vigência no Grupo de Feridas Complexas do Hospital das Clínicas da Faculdade de Medicina da Universidade de São Paulo, com ênfase na seleção do paciente, no tempo de internação, na cobertura cutânea realizada, nas complicações e nas recidivas das lesões. Métodos: coorte retrospectiva de 20 pacientes consecutivos com 25 lesões por pressão Grau IV. Todos os pacientes foram preparados em ambulatório e foram internados para fechamento cirúrgico da lesão por pressão em cirurgia única. Resultados: no total foram confeccionados 27 retalhos para cobertura de 25 feridas abordadas. Foram verificados três casos $(11,1 \%)$ de deiscências menores. Não foi observada recidiva no período de seguimento pós-operatório. Nenhum paciente foi reoperado e nenhum retalho sofreu necrose parcial ou total. O tempo de internação médio foi de 3,6 dias (dois a seis dias) e o seguimento foi de 9,1 meses, em média, oscilando entre dois e 18 meses. Todos os pacientes permaneceram com a lesão fechada e nenhum deles apresentou recidiva da lesão durante o seguimento. Conclusão: o protocolo de internação breve para resolução de lesões por pressão foi considerado adequado, com curto tempo de internação e baixos índices de deiscência de ferida cirúrgica.
\end{abstract}

Descritores: Lesão por Pressão. Ferimentos e Lesões. Retalhos Cirúrgicos. Cirurgia Plástica.

\section{REFERENCES}

1. Milcheski DA, Ferreira MC, Nakamoto H, Tuma Jr P, Gemperli R. Tratamento cirúrgico de ferimentos descolantes nos membros inferiores - proposta de protocolo de atendimento. Rev Col Bras Cir. 2010;37(3):195-203.

2. MC Ferreira. Complex Wounds. Clinics. 2006;61(6):571-8.

3. Phillips $T$, Stanton B, Provan A, Lew R. A study of the impact of leg ulcers on quality of life: financial, social, and psychologic implications. J Am Acad Dermatol. 1994;31(1):49-53.

4. Pokorny ME, Rose MA, Watkins F, Swanson M, Kirkpatrick MK, Wu Q. The relationship between pressure ulcer prevalence, body mass index, and braden scales and subscales: a further analysis. Adv Skin Wound Care. 2014;27(1):26-30.

5. National Pressure Ulcer Advisory Panel. Pressure ulcer definition and stages [Internet]. Washington: NPUAP; 2007. [cited 2007 Apr 13]. Available from: http://www.npuap.org/

6. Alves P, Mota F, Ramos P, Vales L. Epidemiologia das úlceras de pressão: interpretar dados epidemiológicos como indicador de qualidade [Internet]. Berlin: ResearchGate; 2007. [cited 2007 Apr 25] Available from: https://www.researchgate. net/publication/257140360

7. Brito PA, de Vasconcelos Generoso S, Correia MI. Prevalence of pressure ulcers in hospitals in Brazil and association with nutritional status--a multicenter, cross-sectional study. Nutrition. 2013;29(4):646-9.
8. Eslami V, Saadat S, Habibi Arejan R, Vaccaro AR, Ghodsi SM, Rahimi-Movaghar V. Factors associated with the development of pressure ulcers after spinal cord injury. Spinal Cord. 2012;50(12):899-903.

9. Byrne DW, Salzberg CA. Major risk factors for pressure ulcers in the spinal cord disabled: a literature review. Spinal Cord. 1996;34(5):255-63.

10. Costa MP, Sturtz G, Costa FPP, Ferreira MC, Barros Filho TEP. Epidemiologia e tratamento das úlceras de pressão: experiência de 77 casos. Acta Ortop Bras. 2005;13(3):124-33.

11. Alvarez OM, Fernandez-Obregon A, Rogers RS, Bergamo L, Masso J, Black M. Chemical debridement of pressure ulcers: a prospective, randomized, comparative trial of collagenase and papain/urea formulations. Wounds. 2000;12(2):15-25.

12. Quassem A, Humphrey LL, Forciea MA, Starkey M, Denberg TD. Treatment of pressure ulcers: a clinical practice guideline from the American College of Physicians. Ann Intern Med. 2015;162(5):370-9.

13. Barreiro GC, Millan LS, Nakamoto H, Montag E, Tuma Jr PT, Ferreira MC. Reconstruções pelveperineais com uso de retalhos cutâneos baseados em vasos perfurantes: experiência clínica com 22 casos. Rev Bras Cir Plást. 2011;26(4):680-4.

14. Yamamoto $Y$, Ohura $T$, Shintomi $Y$, Sugihara $T$, Nohira K, Igawa $\mathrm{H}$. Superiority of the fasciocutaneous flap in reconstruction of sacral pressure sores. Ann Plast Surg. 1993;30(2):116-21.

15. Sugino H, Hashimoto I, Tanaka $Y$, Ishida S, Abe $Y$, Nakanishi $\mathrm{H}$. Relation between the serum albumin level and nutrition supply in patients with pressure 
ulcers: retrospective study in an acute care setting. J Med Invest. 2014;61(1-2):15-21.

16. Thomas DR. Role of nutrition in the treatment and prevention of pressure ulcers. Nutr Clin Pract. 2014;29(4):466-72.

17. Ricci JA, Bayer LR, Orgill DP. Evidence-based medicine: the evaluation and treatment of pressure injuries. Plast Reconstr Surg. 2017;139(1):275e-286e.

18. Ubbink DT, Brölmann FE, Go PMNYH, Vermeulen $\mathrm{H}$. Evidence-based care of acute wounds: a perspective. Adv Wound Care. 2015;4(5):286-94.

19. Pineda C, Espinosa R, Pena A. Radiographic imaging in osteomyelitis: the role of plain radiography, computed tomography, ultrasonography, magnetic resonance imaging, and scintigraphy. Semin Plast Surg. 2009;23(2):80-9.
20. Sameem M, Au M, Wood T, Farrokhyar F, Mahoney J. A systematic review of complication and recurrence rates of musculocutaneous, fasciocutaneous, and perforator-based flaps for treatment of pressure sores. Plast Reconstr Surg. 2012;130(1):67e-77e.

Received in: 18/07/2017

Accepted for publication: 23/08/2017

Conflict of interest: none.

Source of funding: none.

\section{Mailing address:}

Dimas André Milcheski

E-mail: drdimasandre@gmail.com / dimas.milcheski@hc. fm.usp.br 